\section{A case of two conductors}

\section{T. J. Shankland}

Electrical conductivity of the lower continental crust has presented a persistently irksome problem for interpretation in geological terms. From geophysical techniques such as magneto-tellurics, the lower crust seems to be a fairly good electrical conductor, having conductivities above $10^{-6} \mathrm{~S} \mathrm{~m}^{-1}$, usually in the range $10^{-4}$ $10^{-2} \mathrm{~S} \mathrm{~m}^{-1}$; yet laboratory measurements on typical crustal rocks seem to fall orders of magnitude below these values unless temperatures approach the melting point ${ }^{1}$. We are driven to hypothesize that in situ crustal rocks contain other conducting phases that seem absent in most specimens used for laboratory measurements. On page 136 of this issue ${ }^{2}$ Bailey et al. argue that the elusive conductive phases are saline fluids, whereas on page 134 Frost et al ${ }^{3}$ present a case for the presence of graphite precipitated from a $\mathrm{CO}_{2}$-rich fluid during cooling. Because sea water and silicate melts have conductivities of the order of $3 \mathrm{~S} \mathrm{~m}^{-1}$ and graphite, $10^{4}$ $\mathrm{S} \mathrm{m} \mathrm{m}^{-1}$, only small quantities of either material are required to explain the small conductivities above, provided that the conducting phases are interconnected.

These alternative hypotheses may not be as mutually exclusive as they appear. For one thing, Bailey et al. describe field measurements in a region for which there are not samples obtained from depth, whereas Frost et al. investigate a conductive phase in metamorphic rocks that they consider representative of the lower crust and that were obtained at the surface in a region where crustal conductivity was not measured. In both cases the arguments could apply to old shield areas (tectonically stable regions) where temperatures are relatively low so that partial melt is not an issue. (In active metamorphic zones or volcanic regions one would expect fluids and melts which are near lithostatic pressure and are capable of broad crustal permeation.)

Bailey et al. find horizontal conducting layers that cross a tilted Proterozoic thrust fault, the Ivanhoe Lake cataclastic zone in northern Ontario, and attribute the layers to the presence of conductive fluids. In contrast to the observed layered structure, if the conducting phases were differing contents of sulphides or graphite in the structures on either side of the fault, then it would be reasonable to expect differing conductivities at different depths on opposite sides of the fault. However, there is only a slight break where the fault intersects the conducting layers. There is a substantial history of quantitative interpretation of crustal conductivity in terms of fluid content ${ }^{4.5}$, and superdeep holes in ancient crust ${ }^{6}$ reveal surprising amounts of fluid, consistent with at least the conducting layers in the upper $6 \mathrm{~km}$ observed by Bailey et al.. But there remains some petrological discomfort ${ }^{7}$ with the notion that interconnection of a conducting fluid phase could persist over geological times without its incorporation into relatively insulating hydrated phases $^{8}$ at warmer temperatures below $10-15 \mathrm{~km}$, the depth of their deeper high conductivity layer, unless the fluid is sealed by hydrated minerals in fractures rather than on a grain boundary scale ${ }^{1}$.

Frost et al. use a scanning auger multiprobe to identify grain boundary coatings of carbon having thickness of the order of $1,000 \AA$; mapping this thin layer is a remarkable advance in petrographic observation. The authors' calculation of electrical conductivity for an intergranular conducting fabric suggests that a conducting phase having this texture could account for observed crustal conductivities. Such an approach also has other support. Mathez and Delaney observed grain-boundary carbon on intergranular surfaces in mantle olivine and favoured a similar, late-stage carbon precipitation mechanism rather than a permanent mantle condition. Sternberg ${ }^{10}$ actually described high carbon contents in rocks from the Canadian shield at the same location where he measured conductivity profiles.

These two papers break new ground in their different kinds of observation. To the extent that their work can be taken as representative of other geological regions, they have narrowed the range of speculation about solutions of a long-standing problem to two mechanisms. With more work along these lines we may find ourselves looking not for a single explanation that works in nearly every case but for the explanation that fits each region.

T. J. Shankland is in the Geophysics Group and the Institute of Geophysics and Planetary Physics, Los Alamos National Laboratory, Los Alamos, New Mexico 87545, USA

1. Shankland, T.J. \& Ander, M.E. J. geophys. Res. 88 9745-9484 (1983)

2. Bailey, R.C., Craven, J.A., Macnae, J.C. \& Polzer, B.D. Nature 340, 136-138 (1989)

3. Frost, B.R., Fyfe, W.S., Tazaki, K. \& Chan, T. Nature 340 134-136 (1989).

4. Brace. W.F. in The Structure and Physical Properties of the Earth's Crust. Geophys. Monogr. Ser. vol. 14 (ed. Heacock, J.G.) 243-255 (Am. geophys. Un., Washington DC, 1968).

5. Hyndman, R.D. \& Hyndman, D.W. Earth planet. Sci. Lett. 4, $427-432$ (1968)

6. Lavrushko, I.P., Byelevski, G.A., Prizov, Y.Y. \& Stolyarov, D.E. The Superdeep Well of the Kola Peninsula (Springer, Berlin, 1986)

7. Wannamaker, P.E. J. geophys. Res. 91, 6321-6327 (1986).

8. Olhoeft, G.R. J. geophys. Res. 86, 931-936 (1981)

9. Mathez, E.A. \& Delaney, J.R. Earth planet. Sci. Lett. 56. 217-232 (1981).

10. Sternberg, B.K. J. geophys. Res. 84, 212 (1979).
Against the law

THESE days, technical progress is being increasingly obstructed by legal process. In the United States, that cutting edge of capitalism, some products like vaccines, anaesthetics and light aircraft have been almost driven off the market by the risk of product-liability lawsuits. Others like step ladders and medical services have prices heavily inflated by insurance against legal claims. Daedalus, whose product liability problems at DREADCO are clearly extreme, has in self defence set his mathematicians to develop a computer model of the legal process.

Their basic assumption is that the rights and wrongs of the matter can be ignored. The chance of a lawsuit succeeding is a function purely of the money deployed by either side: the fees of the retained lawyers (or in the case of 'no win, no fee' suits, their income from past wins) and the insurance premiums paid against the liability. All these sums depend on the outcome of past actions, and therefore present a good numerical guide to this one. The likely award will also be a function of time; for award levels seem to increase monotonically. The various parameters of SUE (as the model is called) will be adjusted till it correctly predicts the outcome of most past lawsuits. It will then enable DREADCO to sue others, or react to being sued itself, by pure game theory, without the need for costly legal advice.

With the usual naive logic of computer routines, SUE has already generated some intriguing strategies. One is a 'negative insurance policy' in which the insurance company pays premiums to DREADCO in return for a huge payout to the insurers if DREADCO is sued. Legal action will therefore instantly bankrupt DREADCO, leaving the plaintiff with no prospect of any profit. This 'poison-pill' should be a powerful deterrent.

But when SUE has fully proved itself as a robust and effective program, Daedalus plans to sell it in the open market. Once every potential litigant has SUE and knows that his opponent has it as well, litigation will lose much of its point. All concerned will be able to simulate their legal action instead of having to fight it out for real. Not being egged on by expensive and ingenious lawyers, they will probably soon reach an amicable settlement.

The legal profession will doubtless fight back. It will attempt to outflank SUE by ever wider and more generous judgements of liability. The logical end of this process, muses Daedalus, would be the final assertion of everybody's limitless liability to everybody else for everything. So just when the socialist world is grudgingly seeing the virtues of capitalism, the capitalist world could find itself legally obliged to adopt the purest socialism.

David Jones 